\title{
Humanização na Saúde e Atendimento Interdisciplinar a Portadores da Síndrome do Túnel do Carpo
}

\author{
Ortiz, Marta Cristina Meirelles; Paiva, Gisele; Manginelli, Caterina Pigorini; Santos, \\ Fabíola Epifânio dos; Machado, Styfany Corrêa Batista; Brito, Eduardo Salles; \\ Toledo, Tullio Pieroni \\ Unifesp - Baixada Santista — martacris_o@outlook.com
}

Introdução: a Síndrome do Túnel do Carpo (STC) é caracterizada pela compressão do nervo mediano na área em que este atravessa a região do carpo. Além de sintomas físicos dolorosos e incômodos que podem resultar em limitação de atividade e incapacidade para o trabalho, a STC está ligada a sintomas afetivos e emocionais, bem como mudanças no âmbito familiar, no trabalho e no auto-cuidado que podem refletir na adesão ao tratamento proposto. Os pacientes vivenciam angústia por seu quadro não ser visível, o que gera descaso social e familiar. em virtude de tais demandas, identificadas pela equipe do ambulatório de terapia de mão de um grande hospital, foi proposto um trabalho interdisciplinar de cuidado integral a um grupo de portadores de STC, envolvendo estagiários e docentes dos Cursos de Psicologia e de Terapia Ocupacional de uma universidade pública, com base no princípio pedagógico de formação de profissionais voltados para o trabalho interdisciplinar e humanização da saúde. Objetivos: Geral: Oferecer aos pacientes de um grupo de portadores de STC um tratamento que vá além da reabilitação física, identificando e propondo respostas a demandas que não são apenas da doença ou do trauma físico, mas interferem no tratamento e, mais ainda, na vida do sujeito como um todo. Específicos: (1) Tornar o grupo de reabilitação um espaço de identificação com o outro, troca de experiências, acolhimento, socialização, ampliação da rede de suporte social entre os participantes, sendo abordadas suas demandas físicas e emocionais. (2) Proporcionar aos alunos de ambos os cursos a possibilidade de uma integração entre teoria e prática, por lidar direta e pessoalmente com as questões ligadas à intedisciplinaridade e à intersubjetividade nas relações que envolvem equipes de saúde, profissionais e pacientes no contexto da instituição hospitalar. Resultados: Durante 16 encontros foram desenvolvidas atividades de reabilitação de membros superiores integradas a técnicas de redução de ansiedade e rodas de conversa temáticas entre profissionais e pacientes, que possibilitaram a expressão de sentimentos e sensações decorrentes do quadro clínico e a discussão de situações que direta ou indiretamente interferem no tratamento. em resultado, o grupo de pacientes apresentou melhor capacidade de automonitoramento frente a pensamentos disfuncionais e à ansiedade, tornando-se mais participativo e ativo frente à doença e suas consequências sociais e familiares. Conclusão: Este trabalho promove a participação social de seus agentes, contribuindo para o desenvolvimento de instrumental teórico e metodológico capaz de transformar as tradicionais práticas de educação em saúde e de autonomia para os sujeitos. Desta forma, sugere-se a continuidade da parceria desenvolvida entre universidade e serviço, para que profissionais e estagiários de Psicologia e Terapia Ocupacional possam promover um cuidado integral e humanizado às necessidades do portador de Síndrome do Túnel do Carpo.

Ortiz, Marta Cristina Meirelles; Paiva, Gisele; Manginelli, Caterina Pigorini; Santos, Fabíola Epifânio dos; Machado, Styfany Corrêa Batista; Brito, Eduardo Salles; Toledo, Tullio Pieroni. Humanização na Saúde e Atendimento Interdisciplinar a Portadores da Síndrome do Túnel do Carpo. In: Anais do Congresso Internacional de Humanidades \& Humanização em Saúde [= Blucher Medical Proceedings, num.2, vol.1]. São Paulo: Editora Blucher, 2014. ISSN 2357-7282

DOI 10.5151/medpro-cihhs-10402 